\title{
Caracterização de ninhos e atividade forrageadora de Trachymyrmex fuscus Emery (Hymenoptera, Formicidae) em plantio de eucalipto
}

\author{
Márcio Silva Araújo ${ }^{1}$ \\ Terezinha M.C. Della Lucia ${ }^{1}$ \\ Antônio José Mayhé-Nunes ${ }^{2}$
}

\begin{abstract}
ABTRACT. Caracterization of nest and foraging activity of Trachymyrmex fuscus Emery (Hymenoptera, Formicidae) in Eucalyptus stand. Seven nests of T. fuscus Emery, 1834 have been studied for their structure. These nests, which opened at the soil surface, had two to four chambers located one above the other. Externally all of these nests presented a heap of brownish-yellow debris that was constituted basically by remains of vegetable material. The total nest population was, on average, 1,048 individuals. The diel pattern of foraging of this species was studied for four consecutive months on two nests. This activity occurred predominantly in the night period, and the workers transported, mainly, dry vegetation to the nest.

KEY WORDS. Attini, fungus-growing ants, caracterization of nest, foraging activity
\end{abstract}

Formigas dos gêneros Mycocepurus Forel, 1893, Sericomyrmex Mayr, 1865 e Trachymyrmex Forel, 1893 (Formicidae, Myrmicinae, Attini), também cultivadoras de fungo (WEBER 1945), têm sido constatadas em altas densidades em plantios comerciais de eucalipto em Minas Gerais (PACHECO et al. 1989; ARAÚJO et al. 1997). Essas formigas utilizam como substrato para o cultivo de seu fungo, fezes de insetos, resíduos vegetais em decomposição e eventualmente, partes vivas de plantas (WHEELER 1907; WEBER 1966; PACHECO \& BERTI FILHO 1987; HÖLLDOBLER \& WILSON 1990).

O gênero Trachymyrmex, diferentemente de Acromyrmex Mayr, 1865 (quenquéns) e Atta Fabricius, 1804 (saúvas), apresenta colônias menores, com operárias monomórficas ou com leve polimorfismo (WEBER 1945, 1979; WILSON 1971). Essas pequenas colônias têm sido relatadas como pragas potenciais para a cultura do eucalipto, pelo fato de danificarem as gemas iniciais das touças (PACHECO et al. 1989). Entretanto, existem controvérsias a esse respeito (MAYHÉ-NUNES \& JAFFÉ 1997; MATRANGOLO 1998).

Atualmente, Trachymyrmex fuscus Emery, 1834 está em sinonímia com Trachymyrmex urichi Forel, 1893 (MAYHÉ-NUNES 1991), no entanto sua situação nomenclatural encontra-se sob revisão (Dr. Mayhé-Nunes, comunicação pessoal)

1) Departamento de Biologia Animal, Universidade Federal de Viçosa. 36571-000 Viçosa, Minas Gerais, Brasil.

2) Departamento de Biologia Animal, Universidade Federal Rural do Rio de Janeiro. Rodovia BR 465, Km 07, 23890-000 Seropédica, Rio de Janeiro, Brasil. 
Altas densidades e freqüências de ninhos de T. fuscus foram observadas em plantio comercial de eucalipto na região de Paraopeba, Minas Gerais (ARAÚJO et al. 1997). Essa alta infestação aliada à carência de estudos básicos sobre a espécie, tem propiciado equívocos nas recomendações para o seu controle. Em função disso, este trabalho propôs caracterizar os ninhos de $T$. fuscus observados nessa mesma região, bem como estudar aspectos do forrageamento dessa espécie.

\section{MATERIAL E MÉTODOS}

Este trabalho foi realizado no período de novembro de 1994 a fevereiro de

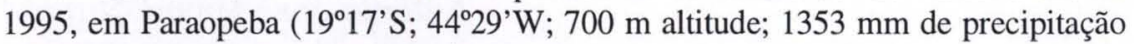
anual; temperatura mínima e máxima anual de 1 e $24^{\circ} \mathrm{C}$, respectivamente) em área de brotação de Eucalyptus camaldulensis Dehnh., de propriedade da V \& M Florestal.

\section{Caracterização dos ninhos de $T$. fuscus}

Sete ninhos de $T$. fuscus escolhidos aleatoriamente na área foram sacrificados com brometo de metila e, após 24 horas, foram escavados. As câmaras e canais foram marcados com talco aplicado por meio de uma "bomba tamanduá", facilitando-se assim sua visualização, conforme metodologia usada por ARAÚJO \& DELLA LUCIA (1997). Essa escavação consistiu na abertura de uma trincheira aberta ao lado do ninho para expor progressivamente os canais e câmaras. Mediram-se os maiores comprimento, largura e altura de todas as câmaras, bem como a profundidade das mesmas em relação à superfície do solo. $\mathrm{O}$ volume de fungo de cada colônia foi estimado, e em seguida, foi recolhido em sacos plásticos juntamente com todo o lixo, operárias e formas jovens mortas que se encontravam no interior das colônias. Esse material foi pesado e homogeneizado em laboratório para a retirada de amostras a serem usadas na determinação da população de larvas, pupas e adultos da colônia. Essa amostragem consistiu na retirada de cinco subamostras de oito gramas de todo o material do ninho. Os voucher specimens foram depositados no Museu de Entomologia da Universidade Federal de Viçosa.

\section{Atividade forrageadora de $T$. fuscus}

O ritmo de atividade diária de forrageamento de $T$. fuscus em condições de campo foi avaliado mensalmente, em dois ciclos consecutivos de 24 horas, durante quatro meses (novembro de 1994 a fevereiro de 1995) em duas colônias, denominadas $\mathrm{C} 1$ e C2. A avaliação foi executada por meio da contagem, durante cinco minutos a cada hora do número de operárias que retornavam para o ninho carregando substrato vegetal, que, freqüentemente, foram fragmentos secos e recortados. Esse método tem sido habitualmente usado para estimar a atividade forrageadora de colônias de formigas (MACIEL et al. 1995; ARAúJO 1996; ARAÚJO et al. 1998).

As avaliações noturnas foram executadas com o auxílio de uma lanterna, cujo foco era coberto com papel-celofane vermelho, para não interferir no comportamento das formigas (GUAJARÁ et al. 1990).

Imediatamente após cada contagem de operárias, foram registradas a temperatura e a umidade relativa do ar, com um termo-higrógrafo posicionado em um tronco de eucalipto, próximo aos ninhos, a uma altura de $1,5 \mathrm{~m}$ em relação à superfície do solo. 
A cada mês, no primeiro ciclo de 24 horas, registrou-se o horário de maior pico de forrageamento, ou seja, o maior número de operárias saindo para buscar substrato para o fungo. Esse horário, no segundo ciclo de 24 horas, foi utilizado para a marcação do comprimento das trilhas e a marcação das áreas de forrageamento das duas colônias, visto que as colônias eram de pequeno porte e isso facilitava a visualização das atividades.

As áreas de forrageamento das colônias foram marcadas, com auxílio de estacas, seguindo-se dez operárias de cada colônia até a sua área de corte. As áreas de forrageamento, foram determinadas pelo perímetro externo dos dez pontos de coleta em relação ao olheiro de entrada do ninho (MENDES et al. 1992; ARAúJo 1996). Esses dados foram plotados em escala apropriada para o papel milimetrado, sendo a área equivalente recortada e medida com o auxílio de medidor de área foliar. Esse procedimento foi repetido nos quatro meses de estudo.

\section{RESULTADOS E DISCUSSÃO}

\section{Caracterização dos ninhos}

Assim como em observações feitas por WEBER (1945) e PACHECO (1991) para $T$. urichi, todos os ninhos de T. fuscus avaliados apresentaram, externamente, seu único olheiro na forma de um canudo de barro de terra semi-endurecida. O diâmetro médio da entrada dos olheiros foi de $1,5 \mathrm{~cm}$. Próximo a esse olheiro, todos os ninhos apresentaram um amontoado de lixo de coloração marrom-amarelada, constituído em grande parte de resto do substrato utilizado para o cultivo de seu fungo (Fig. 1a).

Os ninhos escavados apresentaram profundidade máxima variando de 111 a $208 \mathrm{~cm}$, com duas a quatro câmaras, sendo o número mais freqüente igual a três (Tab. I). Essas câmaras dispunham-se simetricamente sobrepostas (Fig. 1b). A pequena variação na morfometria das câmaras e canais sugere um padrão de confecção de ninho por essa espécie de formiga. Em pequeno relato sobre descrição de ninhos de T. urichi, WEBER (1945) mencionou que essa formiga apresenta as câmaras num formato elíptico, semelhante ao observado neste trabalho para $T$. fuscus. Esse mesmo autor relatou ainda que o número de câmaras variou de uma a cinco. Essa variação no número de panelas, também verificada neste experimento para T. fuscus, pode ter ocorrido devido a diferentes idades das colônias.

Não ocorreu grande variação no volume de fungo, bem como no número de indivíduos encontrados dentro dos ninhos, 1.048 em média, incluídos larvas, pupas e adultos (Tab. II). Não foram encontrados alados nessas colônias que foram escavadas no mês de março de 1995. O número médio de operárias por colônia relatado nesse trabalho $(863,73)$ assemelha-se aos valores apresentados por WEBER (1966) para T. urichi. Esses números são pequenos, quando comparados, por exemplo, com ninhos médios de Acromyrmex subterraneus subterraneus Forel, 1893, que podem apresentar uma população total de 20.872 indivíduos (PEREIRA \& Della LuCia 1998) e ninhos de Atta vollenweideri Forel, 1939 que, com idade em torno de 7,4 anos, podem possuir em média quatro milhões de indivíduos (JOKMAN 1977). 
Tabela I. Dimensões (cm) dos ninhos de Trachymyrmex fuscus escavados em áreas povoadas com Eucalyptus camaldulensis. Paraopeba, Minas Gerais, 1995. (D.P.) Desvio padrão; (*) Comprimento $\times$ Largura $\times$ Altura.

\begin{tabular}{|c|c|c|c|c|c|c|c|c|c|}
\hline Ninho & $\begin{array}{c}\text { Profundidade } \\
\text { da } \\
1^{\text {a câmara }}\end{array}$ & $\begin{array}{l}1^{\mathrm{a}} \text { câmara } \\
C \times L \times A^{*}\end{array}$ & $\begin{array}{c}\text { Distância } \\
\text { entre a } 1^{\frac{\mathrm{a}}{e}} \\
\text { a } 2^{\mathrm{a}} \text { câmara }\end{array}$ & $\begin{array}{l}2^{a} \text { câmara } \\
C \times L \times A\end{array}$ & $\begin{array}{c}\text { Distância } \\
\text { entre a } 2^{\mathrm{a}} \mathrm{e} \\
\text { a } 3^{\mathrm{a}} \text { câmara }\end{array}$ & $\begin{array}{l}3^{a} \text { câmara } \\
C \times L \times A\end{array}$ & $\begin{array}{c}\text { Distância } \\
\text { entre a } 3^{\mathrm{a} e} \\
\text { a } 4^{\mathrm{a}} \text { câmara }\end{array}$ & $\begin{array}{c}4^{\mathrm{a}} \text { Câmara } \\
\mathrm{C} \times \mathrm{L} \times \mathrm{A}\end{array}$ & $\begin{array}{l}\text { Profundidade } \\
\text { máxima do } \\
\text { ninho }\end{array}$ \\
\hline 1 & 5,0 & $5 \times 5 \times 4$ & 20 & $5 \times 7 \times 6$ & 67 & $19 \times 18 \times 12$ & 80 & $20 \times 19 \times 11$ & 208 \\
\hline 2 & 5,3 & $5 \times 4 \times 2$ & 24 & $15 \times 13 \times 7$ & 26 & $21 \times 20 \times 9$ & 30 & $17 \times 21 \times 8$ & 111 \\
\hline 3 & 6,7 & $4 \times 4 \times 3$ & 30 & $7 \times 7 \times 5$ & 120 & $33 \times 21 \times 14$ & - & - & 179 \\
\hline 4 & 4,5 & $3 \times 3 \times 3$ & 21 & $7 \times 9 \times 5$ & 72 & $23 \times 17 \times 13$ & - & - & 118 \\
\hline 5 & 4,8 & $5 \times 3 \times 4$ & 18 & $13 \times 13 \times 8$ & 82 & $18 \times 22 \times 10$ & - & - & 126 \\
\hline 6 & 5,0 & $4,0 \times 3,0 \times 3,0$ & 22 & $11 \times 13 \times 8$ & 150 & $25 \times 19 \times 13$ & - & - & 201 \\
\hline 7 & 5,3 & $5,0 \times 4,0 \times 4$ & 99 & $17 \times 19 \times 11$ & - & - & - & - & 119 \\
\hline Média & 5,2 & $4,4 \times 3,6 \times 3,3$ & 34 & $11 \times 12 \times 7$ & 86 & $23 \times 19 \times 12$ & 55 & $19 \times 20 \times 10$ & 152 \\
\hline D.P. & 0,91 & $0,8 \times 0,8 \times 0,8$ & 29,1 & $4,5 \times 4,3 \times 2,1$ & 43,41 & $5,5 \times 1,9 \times 1,9$ & 35,35 & $2,1 \times 1,4 \times 2,1$ & 42,56 \\
\hline
\end{tabular}

Tabela II. Composição da população dos ninhos de Trachymyrmex fuscus escavados em povoamento de Eucalyptus camaldulensis. Paraopeba, Minas Gerais. Valores entre parênteses correspondem à porcentagem de massa de material amostrado em relação à massa total.

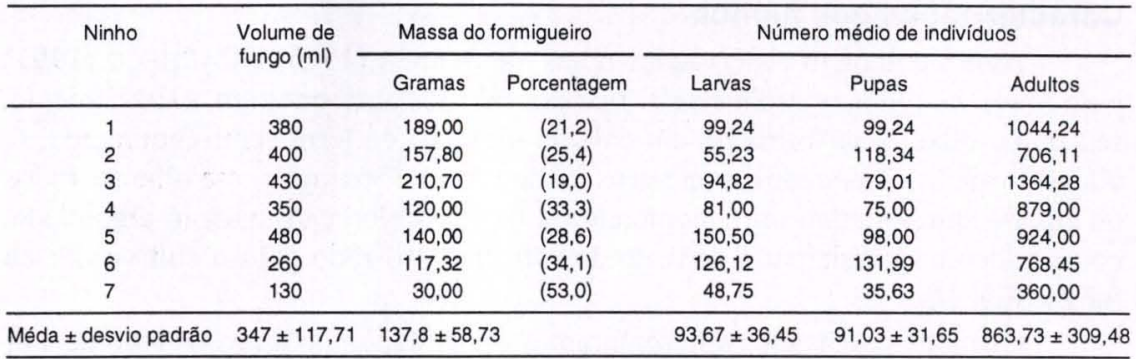

\section{Atividade forrageadora}

As áreas de forrageamento das colônias C1 e C2 variaram de 0,90 a 1,85 $\mathrm{m}^{2}$ e 0,40 a $1,2 \mathrm{~m}^{2}$, respectivamente (Tab. III). Essa variação provavelmente deveu-se à dispersão do principal substrato forrageado ao longo dos meses, que na sua grande maioria, era constituído de folhas de eucalipto secas e presas ao ramo, que se desprendiam das plantas e caíam ao chão, próximo ao ninho. Durante todo o estudo de forrageamento de $T$. fuscus, verificou-se que as operárias não cortaram plantas vivas de eucalipto. Considerando-se a elevada densidade e freqüência de seus ninhos na área experimental, conforme ARAÚJO et al. (1997), pode-se inferir que a espécie não tem importância econômica para o eucaliptal em fase de brotação. Isso corrobora observações feitas por MAYHÉ-NUNES \& JAFFÉ (1997) de que espécies do gênero Trachymyrmex raramente cortam partes vivas de plantas.

Apesar das variações diárias e mensais do fluxo de operárias coletoras de substrato para o fungo, a atividade forrageadora das duas colônias estudadas foi composta por uma única jornada de atividade externa ao ninho e sempre constante no período noturno (Fig. 2). Verificou-se, portanto, forrageamento predominantemente noturno e sempre solitário (sem a formação de trilhas). Padrão de forrageamento semelhante foi mencionados por JAFFÉ \& VILLEGAS (1985) para T. fuscus. 

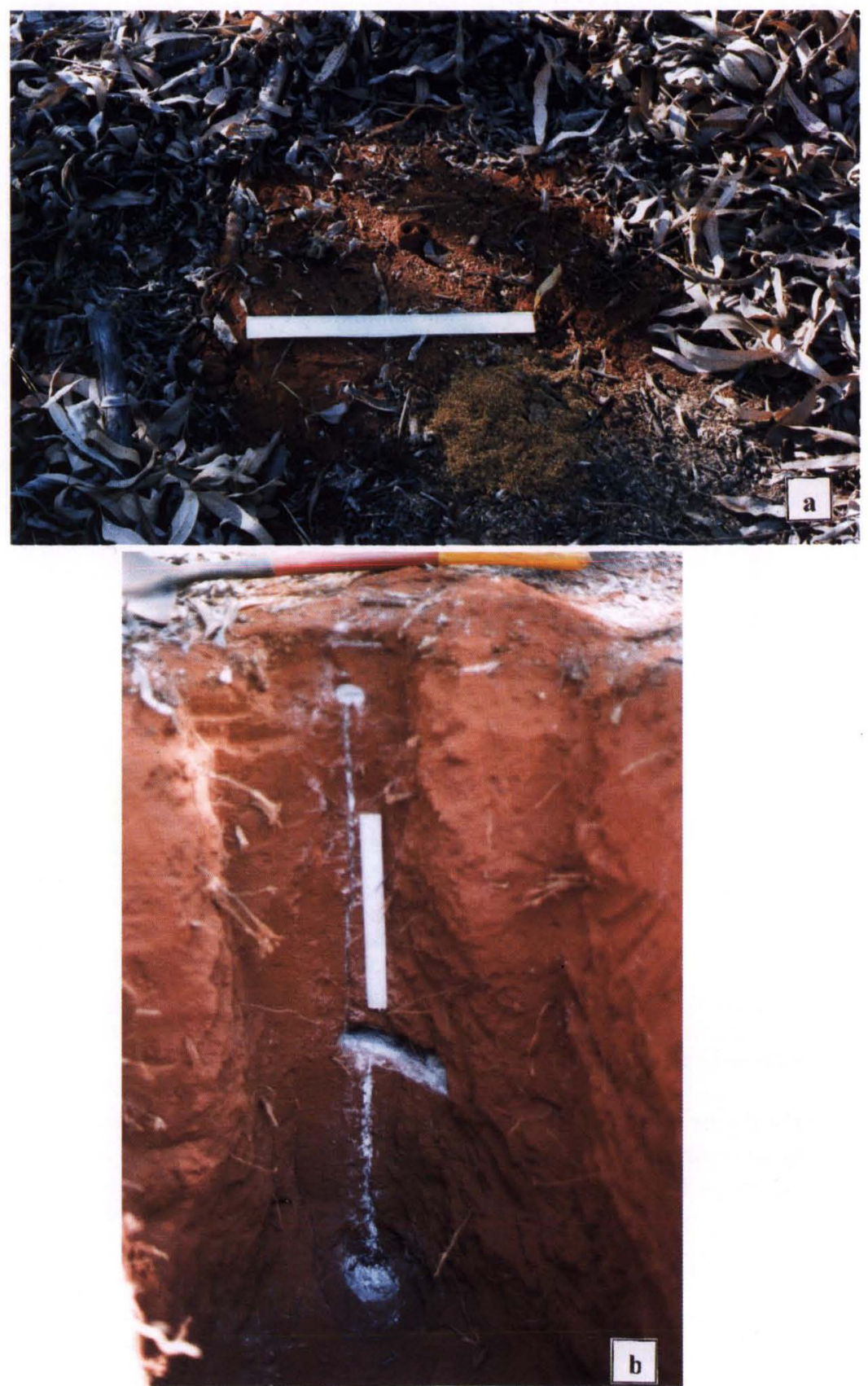

Fig. 1. Aspecto externo (a) e interno (b) de um dos ninhos de Trachymyrmex fuscus. Paraopeba, Minas Gerais, 1995. Escala em branco equivale a $40 \mathrm{~cm}$. 


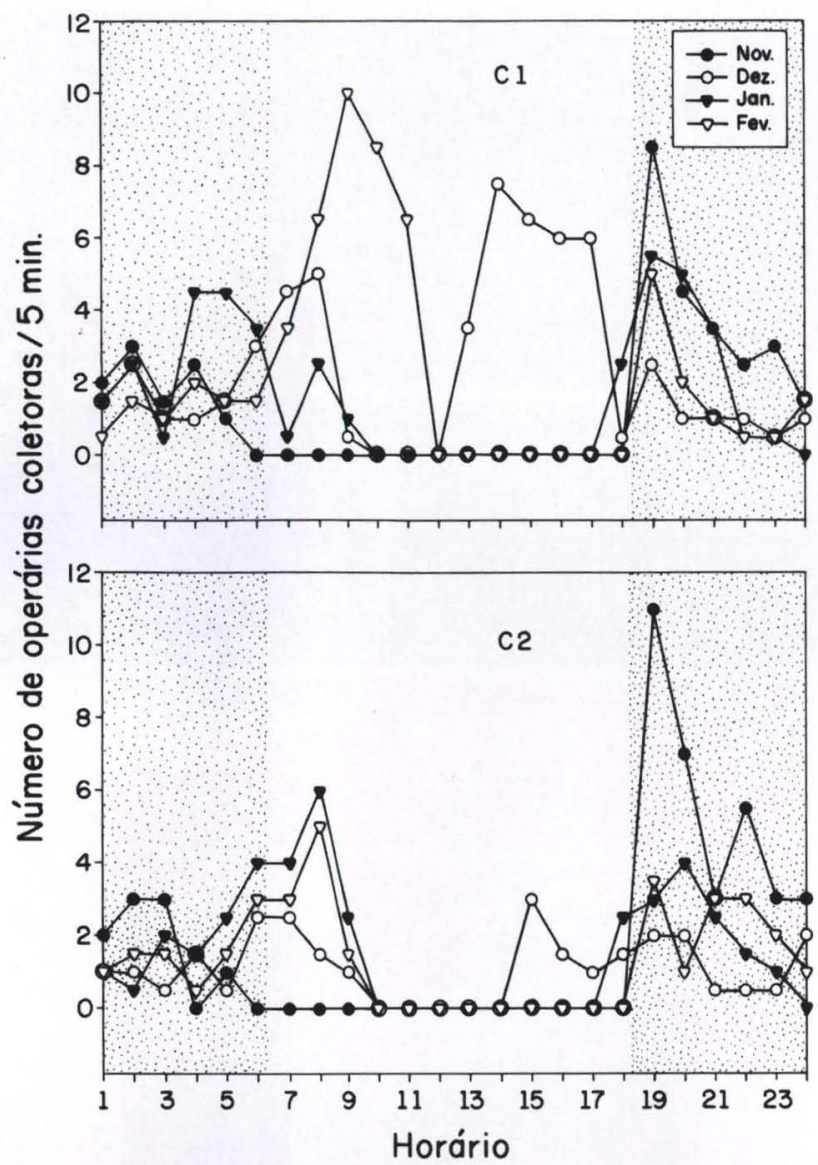

Fig. 2. Ritmo diário da atividade forrageadora das colônias $\mathrm{C} 1$ e $\mathrm{C} 2$ de Trachymyrmex fuscus durante os meses de novembro de 1994 a fevereiro de 1995. Paraopeba, Minas Gerais. As regiões hachuradas correspodem ao periodo de escotofase.

O início da jornada de atividades externas ao ninho para as duas colônias se dava quando ocorria uma queda de temperatura no final da tarde, horário que geralmente coincidia com o entardecer (entre 18:15 e 18:45 h). O mês de dezembro foi uma exceção, pois as operárias permaneceram forrageando quase todo o dia, só paralisando a atividade entre 10 e 12 horas. Essa situação foi observada em ambas as colônias. Em temperaturas superiores a $30^{\circ} \mathrm{C}$, entre 14 e 15 horas, naquele mês, observou-se atividade forrageadora nas colônias. Esse forrageamento diferenciado no mês de dezembro pode ter ocorrido devido à alta precipitação pluviométrica no mês de novembro (Tab. IV), principalmente nos dias que antecederam a avaliação da atividade forrageadora das colônias, que era sempre efetuada no início de cada mês. Desse modo, poderia estar ocorrendo uma certa compensação nessa atividade, em horários sem chuvas. Alterações no padrão diário de forrageamento de formigas 
cortadeiras provocadas por chuvas já foram mencionados por LABRADOR et al. (1972) e ARAÚJO (1996). O horário mais frequiente de encerramento da atividade forrageira foi entre nove e 10 horas, com exceção da colônia $\mathrm{C} 1$, que apresentou pico de atividade forrageadora às nove horas, reduzindo em seguida a sua atividade, até paralisação da mesma às 12 horas.

Tabela III. Áreas de forrageamento das colônias ( $\mathrm{C} 1 \mathrm{e} \mathrm{C2}$ ), durante os quatro meses de estudo (novembro de 1994 a fevereiro de 1995). Paraopeba, Minas Gerais.

\begin{tabular}{ccccc}
\hline \multirow{2}{*}{ Colônia } & \multicolumn{4}{c}{ Áreas de forrageamento $\left(\mathrm{m}^{2}\right)$} \\
\cline { 2 - 5 } & Novembro & Dezembro & Janeiro & Fevereiro \\
\hline C1 & 0,90 & 1,55 & 1,10 & 1,85 \\
C2 & 0,40 & 0,85 & 0,45 & 1,20 \\
\hline
\end{tabular}

Tabela IV. Precipitação pluviométrica local $(\mathrm{mm})$ referente ao período de estudo (novembro de 1994 a fevereiro de 1995). Paraopeba, Minas Gerais.

\begin{tabular}{|c|c|c|c|c|c|}
\hline \multirow{2}{*}{ Dia } & \multicolumn{5}{|c|}{ Meses } \\
\hline & Outubro & Novembro & Dezembro & Janeiro & Fevereiro \\
\hline 1 & 0 & $0^{*}$ & 14,8 & $0^{*}$ & 5,4 \\
\hline 2 & $0^{*}$ & $0^{*}$ & $0^{*}$ & $0^{*}$ & 5,4 \\
\hline 3 & $0^{*}$ & 0 & $0^{*}$ & 12,0 & $3,6^{*}$ \\
\hline 4 & 0 & 12,8 & 0 & 6,8 & $0^{*}$ \\
\hline 5 & 0 & 0 & 0 & 3,6 & 0 \\
\hline 6 & 0 & 0 & 22,2 & 3,2 & 0 \\
\hline 7 & 16,8 & 0 & 2,4 & 0 & 40,8 \\
\hline 8 & 0 & 0 & 48,0 & 0 & 8,2 \\
\hline 9 & 0 & 0 & 4,4 & 0 & 42,0 \\
\hline 10 & 0 & 0 & 15,2 & 0 & 0 \\
\hline 11 & 0 & 0 & 0 & 0 & 38,0 \\
\hline 12 & 0 & 0 & 0 & 12,8 & 25,8 \\
\hline 13 & 0 & 6,0 & 0 & 19,8 & 1,2 \\
\hline 14 & 0 & 0 & 0 & 0 & 0,8 \\
\hline 15 & 0 & 7,2 & 0 & 0 & 30,2 \\
\hline 16 & 0 & 0,9 & 4,8 & 0 & 7,0 \\
\hline 17 & 0 & 0 & 0 & 0 & 0 \\
\hline 18 & 0 & 7,8 & 2,3 & 0 & 1,4 \\
\hline 19 & 1,0 & 34,6 & 45,8 & 0 & 13,8 \\
\hline 20 & 0 & 36,8 & 0 & 0,8 & 3,8 \\
\hline 21 & 0 & 69,4 & 0 & 2,6 & 0 \\
\hline 22 & 0 & 1,4 & 16,4 & 0,6 & 0 \\
\hline 23 & 0 & 0 & 33,4 & 0 & 0 \\
\hline 24 & 0 & 8,2 & 12,0 & 5,6 & 0 \\
\hline 25 & 0 & 0 & 1,0 & 0 & 0 \\
\hline 26 & 0 & 0 & 0 & 1,0 & 0 \\
\hline 27 & 4,2 & 1,2 & 1,0 & 2,8 & 0 \\
\hline 28 & 6,8 & 0,2 & 1,0 & 0 & 0 \\
\hline 29 & 0 & 47,6 & 0 & 0 & - \\
\hline 30 & 6,6 & 14,8 & 0 & 0 & - \\
\hline 31 & 35,4 & - & 0 & 1,8 & - \\
\hline Total & 70,8 & 248,9 & 224,7 & 73,4 & 227,4 \\
\hline
\end{tabular}

(*) Dias dos meses em que foram efetuadas as observações da atividade forrageadora de $T$. fuscus.

Revta bras. Zool. 19 (2): 419 - 427, 2002 
Observou-se uma correlação (Pearson) negativa entre o fluxo de operárias transportadoras de fragmento vegetal e a temperatura do ar, ou seja, o aumento na temperatura implicou em uma diminuição da atividade forrageadora das colônias C1 e C2 (Tab. V). Quanto à umidade relativa do ar, houve uma correlação positiva significativa, somente para a colônia C2 (Tab. V). Isso provavelmente não ocorreu para a colônia $\mathrm{C} 1$ pelo fato das operárias dessa colônia terem apresentado alta atividade forrageadora durante quase todo o dia em observações realizadas no mês de dezembro. O significado dessas correlações entre temperatura e umidade relativa sobre a atividade forrageadora não é bem claro. FOWLER (1979) supõe que flutuações nessas variáveis poderiam promover alterações fisiológicas nas operárias, bem como afetar o balanço hídrico de plantas cortadas, além de alterar a qualidade nutricional das plantas que servem de substrato para o fungo.

Neste trabalho, as colônias $\mathrm{C} 1$ e C2, em todos os meses de estudo, tiveram suas atividades forrageadoras iniciadas ao escurecer, sendo que o término da jornada de atividades externas à colônia variou e, ao que parece, está associado às variáveis climáticas.

Tabela V. Efeito da temperatura e umidade relativa do ar sobre o fluxo de operárias coletoras de Trachymyrmex fuscus durante os meses de novembro de 1994 a fevereiro de 1995. Paraopeba, Minas Gerais.

\begin{tabular}{ccc}
\hline Colônia & Umidade relativa & Umidade relativa \\
\hline C1 & $-0,22^{*}$ & 0,15 \\
C2 & $-0,43^{*}$ & $0,39^{*}$ \\
\hline
\end{tabular}

$\left(^{\star}\right)$ Coeficientes de Correlação de Pearson significativos a $95 \%$ de probabilidade.

AGRADECIMENTOS. Aos Engenheiros, Técnicos Florestais e Funcionários da V \& M Florestal pela ajuda na condução do experimento em Paraopeba, ao Técnico Pedro A. Ribeiro pela colaboração na confecção de uma figura deste artigo e ao CNPq e V \& M Florestal pelo auxílio financeiro.

\section{REFERÊNCIAS BIBLIOGRÁFICAS}

ARAúJo, M.S. 1996. Espécies de formigas cortadeiras e ecologia de Acromyrmex laticeps nigrosetosus Forel, num povoamento de eucalipto. Viçosa, Imprensa Universitária, 51p.

ARaújo, M.S. \& T.M.C. Della LuCia. 1997. Caracterização de ninhos de Acromyrmex laticeps nigrosetosus Forel, em povoamento de eucalipto em Paraopeba, MG. An. Soc. Ent. Brasil 26: 205-207.

Araújo, M.S.; T.M.C. Della Lucia \& A.J. Mayhé-Nunes. 1997. Levantamento de Attini (Hymenoptera, Formicidae) em povoamento de Eucalyptus na região de Paraopeba, Minas Gerais, Brasil. Revta bras. Zool. 14: 323-328.

Araújo, M.S.; T.M.C. Della Lucia; M.C. Picanço; N. Anjos \& E.F. Vilela. 1998. Polimorfismo e transporte de cargas em Acromyrmex laticeps nigrosetosus Forel, 1908 (Hymenoptera: Formicidae). Revta bras. Entomol. 41: 443-446.

FowLER, H.G. 1979. Environmental correlates of the foraging of Acromyrmex crassispinus. Ciência e Cultura 31: 879-882.

Revta bras. Zool. 19 (2): $419-427,2002$ 
GuajarÁ, M.S.; E.F. Vilela; K. JafFé. 1990. Senses used by Acromyrmex subterraneus molestans during homing orientation, under laboratory conditions, p. 363-372. In: R.K. VAN DER MEER; K. JAFFÉ \& A. CEDEÑo (Eds). Applied myrmecology: a world perspective. Boulder, Westview Press, $741 \mathrm{p}$.

Hölldobler, B. \& E.O. Wilson. 1990. The ants. Cambridge, Harvard Univ. Press, 732p.

JAFFÉ, K. \& G. VILLEGAS. 1985. On the comunication systems of the fungus growing ant Trachymyrmex urichi. Insectes Sociaux 32: 257-274.

Jonkman, J.C.M. 1977. Biology and ecology of the leaf-cutting ant Atta vollenweideri Forel, 1898 (Hymenoptera: Formicidae) and its impact in Paraguayan pastures. Lien, 132p.

Labrador, J.R.; Q.I. Martinez \& A. Mora. 1972. Acromyrmex landolti Forel, plaga del pasto Guinea (Panicum maximum) en el Estado Zulia. Revta. Fac. Agronomia, MAracay, 2: 27-38.

Maciel, M.A.F.; T.M.C. Della Lucia; M.S. Araújo; M.A. Oliveira. 1995. Ritmo diário de forrageamento da formiga cortadeira Acromyrmex subterraneus subterraneus Forel. An. Soc. Ent. Brasil 24: 371-378.

Matrangolo, C.A.R. 1998. Efeito do desfolhamento no crescimento de mudas de Eucalyptus grandis e forrageamento de Trachymyrmex sp. (Formicidae: Attini). Viçosa, Imprensa Universitária, 70p.

MAYHÉ-Nunes, A.J. 1991. Estudo de Acromyrmex (Hymenoptera, Formicidae) com ocorrência constatada no Brasil: Subsídio para uma análise filogenética. Viçosa, Imprensa Universitária, $122 \mathrm{p}$.

MaYhÉ-NunES, A.J. \& K. JaFFÉ. 1997. Substratos para os fungos simbiontes dos Attini menores (Hymenoptera, Formicidae). Anais XVI Congresso Brasileiro de Entomologia, Salvador, p. 245.

Mendes, W.B.A; J.A.H. Freire; M.C. Loureiro; S.B. Nogueira; E.F. Vilela \& T.M.C. Della Lucia. 1992. Aspectos ecológicos de Acromyrmex (Moellerius) balzani (Emery, 1890) (Formicidae: Attini) no município de São Geraldo, Minas Gerais. An. Soc. Ent. Brasil 21: 155-168.

PACHECO, P. 1991. Formigas cortadeiras (Hymenoptera: Formicidae) com ênfase as culturas de Pinus e eucaliptos. Piracicaba, ESALQ, 86p.

Pacheco, P. \& E. Berti Filho. 1987. Formigas quenquéns, p.3-21. In: P. Pacheco \& E. Berti Filho (Eds). Formigas cortadeiras e o seu controle. Piracicaba, IPEF, 152p.

Pacheco, P.; E. Berti Filho; F.H. Caetano \& L.Coelho. 1989. O gênero Sericomyrmex em reflorestamentos. Anais IX Encontro de Mirmecologia, Viçosa, Impresa Universitária, Universidade Federal de Viçosa, p. 12-13.

Pereira, R.C. \& T.M.C. Della Lucia. 1998. Estimativa populacional em ninhos de Acromyrmex subterraneus subterraneus Forel, 1893 (Hymenoptera: Formicidae). Revta Ceres, Viçosa, 45: 573-578.

WeBER, N.A. 1966. Fungus growing ants. Science 153: 587-604.

- 1979. Fungus-culturing by ants, p.77-116. In: L.R. BATRA (Ed.). Insect-fungus symbiosis: mutualism and comensalism. Montclair, Allanheld and Osmun, 287p.

WheELER, W.M. 1907. The fungus-growing ants of North America. Bull. Amer. Mus. Nat. Hist. 23: 669-807.

WILSON, E.O. 1971. The insects societies. Massachsetts, The Belknap Press, 548p.

Recebido em 12.IV.2001; aceito em 07.V.2002. 